\title{
Single-institution Retrospective Analysis of Prognostic Factors Influencing Very Late-onset Post-transplant Lymphoproliferative Disorder
}

Rohit Bishnoi ${ }^{1}$, Jordan Minish ${ }^{2}$, Aaron J. Franke ${ }^{3}$, William P. Skelton IV ${ }^{3,2}$, Chintan P. Shah ${ }^{1}$, Yu Wang ${ }^{4}$ , Nam H. Dang 5

1. Hematology and Oncology, University of Florida, Gainesville, USA 2. Internal Medicine, University of Florida, Gainesville, USA 3. Oncology, H. Lee Moffitt Cancer Center and Research Institute, Tampa, USA 4. Health Cancer Center, University of Florida, Gainesville, USA 5. Oncology, University of Florida, Gainesville, USA

Corresponding author: Rohit Bishnoi, rohit.bishnoi@medicine.ufl.edu

\section{Abstract \\ Background}

Post-transplant lymphoproliferative disorder (PTLD) is a rare complication following transplant (solid organ or allogeneic) due to the proliferation of lymphoid cells in the immunosuppressed state. The incidence of PTLD follows a bimodal distribution, with high incidence immediately after transplant (early-onset PTLD), followed by a decline and then a high-incidence again five years after transplantation (late-onset PTLD). This study exclusively aims to identify prognostic factors for the subgroup of PTLD, described as very late-onset PTLD, occurring after 10 years of transplant.

\section{Methods}

This study was conducted at the University of Florida, with the requisite study population identified through the cancer registry. Data were collected by individual chart review and analyzed. Survival estimates and univariate and multivariate analyses were performed to measure the effects of each variable on overall survival.

\section{Results}

A total of 33 patients were identified, with a median age at transplant of 42.3 years, while the median age at PTLD diagnosis was 54.7 years. Median time from transplant to PTLD diagnosis was 13.3 years. Kidney (30.3\%), liver (27.3\%), and heart (24.2\%) transplants were the most common allografts associated with very late PTLD development. The most common pathology was diffuse large B-cell lymphoma (DLBCL) in $45.5 \%$ of patients. CHOP+/-R (cyclophosphamide, doxorubicin hydrochloride (hydroxydaunorubicin), vincristine sulfate (Oncovin), prednisone, rituximab) was the most common chemo regimen used as the initial choice in $36.4 \%$ of patients.

Received 01/22/2020

Review began 01/22/2020 Review ended 02/05/2020 Published 02/07/2020

(c) Copyright 2020 Bishnoi et al. This is an open access article distributed under the terms of the Creative Commons Attribution License CC-BY 4.0., which permits unrestricted use, distribution, and reproduction in any medium, provided the original author and source are credited.
Median survival was 5.4 years. Univariate analysis showed that age at diagnosis over 65, male gender, bone marrow involvement, past medical history $(\mathrm{PMH})$ of malignancy, immunosuppression regimen at PTLD diagnosis, and initial and final best response to treatment were statistically significant $(\mathrm{p}<0.05)$ factors associated with survival. On multivariate analysis, bone marrow involvement was significantly associated with poor survival ( $\mathrm{p}=0.008$ ). Surprisingly, performance status, Epstein-Barr virus (EBV) status, pathology type, Ann-Arbor stage, and chemotherapy regimen were not significantly associated with survival. At the end of the study, $48.5 \%$ of patients achieved complete remission and the allograft survived in $84.8 \%$.

\section{Conclusions}

In this retrospective study of very-late onset PTLD, we identified factors associated with survival different from early and late PTLD. These factors should be considered during the treatment of this subgroup of PTLD patients.

Categories: Internal Medicine, Oncology, Transplantation

Keywords: post transplant lymphoproliferative disorder, late-onset ptld, very late-onset ptld, prognostic factors for ptld, ebv ptld

\section{Introduction}

Post-transplant lymphoproliferative disorder (PTLD) describes the process of the proliferation of lymphoid cells in the immunocompromised state caused by immunosuppressive agents used after the transplant of solid organ or allogeneic stem cells. It was first described in solid organ transplant patients by Doak et al. in 1968 and is a well-documented, albeit rare, complication. It is the leading cause of cancer-related mortality following transplant [1]. The incidence of PTLD is higher after intestinal or multiorgan transplants and the 
lowest after liver or hematopoietic stem cell transplants [2-3]. PTLD incidence has been on the decline over the last few decades, with some studies reporting a decline in incidence from more than $20 \%$ to less than $3 \%$ in a period ranging from 1990 to 2011 [4]. Numerous risk factors place a patient at a higher likelihood of developing PTLD, most importantly, the degree of immunosuppression of $\mathrm{T}$ cells and recipient Epstein-Barr virus (EBV) status [5]. Older age, white race, and time elapsed after transplant have also been described as risk factors [4]. Various single-center institutional studies have analyzed and reported outcomes for PTLD, which remains the main source of clinical information on this rare entity [6-9]. Being one of the largest transplant centers in the southeast United States, we analyzed the outcomes of PTLD at our institution [1012].

In the 2008 World Health Organization (WHO) classification of lymphoma, PTLD was recognized as a separate group of lymphoid malignancies, where PTLD was classified into early-lesion PTLD, polymorphic PTLD, monomorphic PTLD, and classical Hodgkin lymphoma PTLD. The incidence of PTLD follows a bimodal distribution, with a higher incidence immediately after transplant, followed by a decline, and then a high-incidence again five years after transplantation and again extending to more than 10 years after transplant [4,13-15]. This incidence pattern, depending on the time interval between transplant and PTLD diagnosis, has led to another classification of PTLD in the medical literature, early-onset and late-onset PTLD. PTLD occurring within 12 months of transplant is defined as early-onset while PTLD developing after 12 months is described as late-onset PTLD [4,8,16-17]. These two entities have been described to have different risk factors and clinicopathologic features.

Early-onset PTLD is more frequently associated with EBV viremia, CD20 positivity, young age, and allograft involvement while late-onset PTLD is associated more with advanced age, EBV seronegativity, induction therapy with polyclonal antibodies or OKT3, and azathioprine therapy, and has more frequent extra-nodal disease [4,8,17-20]. Recipient EBV seronegativity does increase the risk of early and EBV positive PTLD $[4,20]$. Also, late-onset PTLD tends to be more B-cell in origin and monomorphic pathology, less likely to involve allograft and tends to resemble more with lymphoma in the general population [18,21]. Due to the role of EBV in the pathogenesis of PTLD, especially for early-onset PTLD, EBV viral load monitoring has been utilized by certain institutions as a strategy to decrease PTLD risk, but this has not shown a significant impact on PTLD risk reduction [20]. Viral load monitoring and close follow-up after transplant do help in identifying early PTLD.

The incidence of PTLD has been on the decline but due to the improved survival of grafts with longer immunosuppression, we continue to see new cases of PTLD even a long time after organ transplantation [22-23]. It is important to gather more scientific evidence regarding prognostic factors for late-onset PTLD, as previous studies have shown that these patients tend to have poor survival [4,24-25]. There is another subset of PTLD occurring after a decade of transplant, which has been described in medical literature as 'very-late' onset PTLD [21-22]. Very little is known about factors affecting survival in this subgroup of PTLD, but it has been reported to mainly affect older patients $[21,26]$. Over the last many years, multiple studies have focused on early versus late-onset PTLD, with limited data about PTLD occurring after a decade of transplant. Our literature search showed that apart from a few isolated case reports, only one retrospective study focused on this subgroup [21]. With this study from a large single institution, we aimed to examine prognostic factors influencing the outcomes of 'very-late onset PTLD.' To our knowledge, this is the firstever retrospective single institutional study reported from the United States specifically targeting this subgroup of very late-onset PTLD.

\section{Materials And Methods}

This study was conducted at the University of Florida after institutional review board (IRB) approval and all ethical guidelines were followed.

The study population was identified through the cancer registry at the University of Florida (UF) Health Cancer Center. These patients were diagnosed with PTLD from April 2003 to December 2016 over a span of 14 years. Data were collected by individual chart review. Data collected included patient demographics, transplant, PTLD details, treatments, and outcomes. Data were analyzed as percentages for each variable and survival estimates; univariate and multivariate analyses were performed to measure the effects of each variable on overall survival.

Treatment response was defined as complete response (CR), partial response (PR), stable disease (SD), and progressive disease $(\mathrm{PD})$. The overall response rate (ORR) was defined as $\mathrm{CR}+\mathrm{PR}$ while the disease control rate (DCR) was defined as $\mathrm{CR}+\mathrm{PR}+\mathrm{SD}$.

\section{Statistics method}

Descriptive statistics were calculated for all variables, including the frequency of nominal variables and mean, median, standard deviance of numeric variables. All hazard ratios (HRs) and their $95 \%$ confidence interval were estimated from Cox proportional hazard (CoxPH) models. The Kaplan-Meier method was applied to fit the overall survival functions. Then, the Log-rank test was used to compare the survival curves between subgroups. 


\section{Cureus}

In order to identify the risk factors that were statistically associated with overall survival, univariate and multivariate CoxPH models were performed sequentially. Univariate analysis was performed using variables, including patient characteristics, transplant details, time from transplant to PTLD, immunosuppression details, PTLD characteristics, and treatment details among others. All variables with a p-value of HR less than 0.2 in univariate analysis were selected to enter the multivariate CoxPH model as covariates. Then, a stepwise selection method with an entering p-value of 0.2 and a staying p-value of 0.05 was applied to do the model section.

Without a special remark, all statistically significant levels were defined as $\mathrm{p}<0.05$. Data analysis was conducted with SAS 9.4 (SAS Institute, Cary, North Carolina).

\section{Results}

A total of 33 patients were identified who developed PTLD after 10 years of transplant. The median age at transplant was 42.3 years (range: 2 months - 64.6 years) while the median age at PTLD diagnosis was 54.7 years (range: 11.2 - 79.4 years). Median time from transplant to PTLD diagnosis was 13.3 years (range: 10 18.4 years). Other demographic details are listed in Table 1.

\begin{tabular}{|c|c|c|c|c|c|}
\hline Variables & & $\mathbf{n}$ & $\%$ & Hazard Ratio & p-value \\
\hline \multicolumn{6}{|l|}{ Sex } \\
\hline & Male & 19 & 57.6 & 6.1 & 0.0189 \\
\hline & Female & 14 & 42.4 & & \\
\hline \multirow[t]{5}{*}{ Race } & & & & NSS & \\
\hline & White & 23 & 69.7 & & \\
\hline & Black or African American & 4 & 12.1 & & \\
\hline & Asian & 3 & 9.1 & & \\
\hline & Other & 3 & 9.1 & & \\
\hline \multicolumn{6}{|l|}{ Age group at diagnosis } \\
\hline & Pediatrics & 5 & 15.2 & & \\
\hline & Adults & 21 & 63.6 & & \\
\hline & Elderly & 7 & 21.2 & 3.9 & 0.0267 \\
\hline \multirow[t]{4}{*}{ Induction immunosuppression } & & & & NSS & \\
\hline & Yes & 8 & 24.2 & & \\
\hline & No & 21 & 63.6 & & \\
\hline & UK & 4 & 12.1 & & \\
\hline \multirow[t]{6}{*}{ Allograft type } & & & & NSS & \\
\hline & Kidney & 10 & 30.3 & & \\
\hline & Liver & 9 & 27.3 & & \\
\hline & Heart & 8 & 24.2 & & \\
\hline & Lung & 4 & 12.1 & & \\
\hline & Kidney and pancreas & 2 & 6.1 & & \\
\hline \multirow[t]{4}{*}{ Acute allograft rejection before PTLD } & & & & NSS & \\
\hline & Yes & 16 & 48.5 & & \\
\hline & No & 16 & 48.5 & & \\
\hline & Unknown & 1 & 3.0 & & \\
\hline \multirow[t]{2}{*}{ Tumor EBER status } & & & & NSS & \\
\hline & Positive & 9 & 27.3 & & \\
\hline
\end{tabular}




\section{Cureus}

\begin{tabular}{|c|c|c|c|c|c|}
\hline & Negative & 18 & 54.5 & & \\
\hline & Unknown & 6 & 18.2 & & \\
\hline \multirow[t]{4}{*}{ ECOG status at PTLD diagnosis } & & & & NSS & \\
\hline & $0-2$ & 28 & 84.8 & & \\
\hline & $3-4$ & 4 & 12.1 & & \\
\hline & Unknown & 1 & 3.0 & & \\
\hline \multirow[t]{4}{*}{ CD 20} & & & & NSS & \\
\hline & Positive & 21 & 63.6 & & \\
\hline & Negative & 8 & 24.2 & & \\
\hline & Unknown & 4 & 12.1 & & \\
\hline \multirow[t]{4}{*}{ Extra-nodal sites } & & & & NSS & \\
\hline & Positive & 19 & 57.6 & & \\
\hline & Negative & 11 & 33.3 & & \\
\hline & Unknown & 3 & 9.1 & & \\
\hline \multirow[t]{4}{*}{ Ann-Arbor Stage } & & & & NSS & \\
\hline & $|-| \mid$ & 16 & 48.5 & & \\
\hline & IIII-IV & 15 & 45.5 & & \\
\hline & Unknown & 2 & 6.1 & & \\
\hline \multicolumn{6}{|l|}{ Albumin level } \\
\hline & Normal & 19 & 57.6 & 0.35 & 0.0760 \\
\hline & Low & 12 & 36.4 & & \\
\hline & Unknown & 2 & 6.1 & & \\
\hline \multirow[t]{4}{*}{ IPI Score } & & & & NSS & \\
\hline & $0-2$ & 15 & 45.5 & & \\
\hline & $3-5$ & 10 & 30.3 & & \\
\hline & Unknown & 8 & 24.2 & & \\
\hline \multirow{3}{*}{ PMH of malignancy } & & & & 4.8 & 0.0481 \\
\hline & Yes & 2 & 6.1 & & \\
\hline & No & 31 & 93.9 & & \\
\hline \multirow[t]{4}{*}{ B-symptoms } & & & & NSS & \\
\hline & Yes & 13 & 39.4 & & \\
\hline & No & 17 & 51.5 & & \\
\hline & Unknown & 3 & 9.1 & & \\
\hline
\end{tabular}

\section{TABLE 1: Patient demographics and PTLD details with HR for overall survival}

EBER: Epstein-Barr encoding region, NSS: not statistically significant, IPI: International Prognostic Index, ECOG: Eastern Cooperative Oncology Group, PMH: past medical history; PTLD: Post-transplant lymphoproliferative disorder; HR: hazard ratio

Twenty-four point two percent $(24.2 \%)(\mathrm{n}=8)$ patients received induction immunotherapy and the most commonly used drug was OKT3. The most common initial immunosuppression regimen used after transplant was steroids, cyclosporine, and azathioprine in 51.5\% $(\mathrm{n}=17)$ patients. At the time of PTLD 


\section{Cureus}

diagnosis, tacrolimus alone or in combination with mycophenolate or azathioprine was the most common agent used for immunosuppression in $51.5 \%(\mathrm{n}=17)$ patients.

Donor EBV serostatus data was mostly not available. Recipient EBV serostatus was positive in $45.5 \%(n=15)$ patients before transplant and was positive in 54.5\% ( $\mathrm{n}=18)$ after transplant. The tumor EBV-encoded RNA (EBER) was positive only in $27.3 \%(n=9)$ patients. Over the course of more than 10 years after transplant, $48.5 \%(n=16)$ experienced acute rejections of allograft and $21.2 \%(n=7)$ experienced more than one episode of acute rejection. Chronic allograft rejection was noted in $21.2 \%(n=7)$ patients.

B symptoms were present in $48.5 \%(n=16)$ patients and weight loss was the most common symptom present in $30.3 \%(n=10)$. Six point one percent $(6.1 \%)(n=2)$ patients had a past medical history of other unrelated malignancies.

Monomorphic PTLD was noted in $72.8 \%(\mathrm{n}=24)$ patients and diffuse large B-cell lymphoma (DLBCL) was the most common pathologic subtype noted in $45.5 \%(\mathrm{n}=15)$. Detailed pathologic distribution is outlined in Table 2 .

\begin{tabular}{|c|c|c|c|c|}
\hline PTLD Pathology & Subtypes & B-Cell Subtype & $\mathbf{n}$ & $\%$ \\
\hline \multicolumn{5}{|l|}{ Early lesion PTLD } \\
\hline & Plasmacytic hyperplasia & & 1 & 3.0 \\
\hline Polymorphic PTLD & & & 6 & 18.2 \\
\hline \multicolumn{5}{|l|}{ Monomorphic PTLD } \\
\hline & B-Cell type & & & \\
\hline & & DLBCL & 15 & 45.5 \\
\hline & & Burkitt's & 1 & 3.0 \\
\hline & & Plasma cell myeloma or plasmacytoma like lesion & 3 & 9.1 \\
\hline & & Unspecified B-cell & 3 & 9.1 \\
\hline & T-cell type & & 2 & 6.1 \\
\hline Hodgkın or HL IIKe PILD & & & 2 & 6.1 \\
\hline
\end{tabular}

\section{TABLE 2: PTLD pathologic distribution}

DLBCL: diffuse large B-cell lymphoma, HL: Hodgkin like; PTLD: post-transplant lymphoproliferative disorder

Table 3 shows the details of upfront therapy. As upfront therapy, 15.2\% $(n=5)$ patients were treated with reduced immunosuppression (RIS) alone and $3 \%(n=1)$ was treated with surgery alone. Eighty-one point eight percent (81.8\%) $(n=27)$ received upfront chemotherapy, either rituximab alone or in combination with other chemo drugs. Another $6.1 \%(\mathrm{n}=2)$ patients received chemo after the failure of upfront therapy and thus a total of $87.9 \%(n=29)$ patients required chemotherapy for PTLD treatment. 


\section{Cureus}

\begin{tabular}{|c|c|c|c|c|}
\hline \multirow[t]{2}{*}{ Response } & \multicolumn{2}{|c|}{ Initial Response } & \multicolumn{2}{|c|}{ Final Response } \\
\hline & $\mathrm{n}$ & $\%$ & $\mathrm{n}$ & $\%$ \\
\hline$C R$ & 17 & 51.5 & 16 & 48.5 \\
\hline PR & 5 & 15.2 & 1 & 3.0 \\
\hline SD & 2 & 6.1 & 4 & 12.1 \\
\hline PD & 5 & 15.2 & 7 & 21.2 \\
\hline Unknown & 4 & 12.1 & 5 & 15.2 \\
\hline DCR & 24 & 72.7 & 21 & 63.6 \\
\hline ORR & 22 & 66.7 & 17 & 51.5 \\
\hline
\end{tabular}

\section{TABLE 3: Treatment response after upfront therapy and at the end of the study}

CR: complete remission; PR: partial remission; SD: stable disease; PD: progressive disease; DCR: disease control rate; ORR: overall response rates

Rituximab alone as upfront therapy was used in $18.2 \%$ patients $(n=6)$ and of these six patients, three received further chemotherapy in combination with rituximab. $\mathrm{CHOP}+/ \mathrm{R}$ was the most common chemo regimen used as an initial choice in $36.4 \%(n=12)$ patients. Another $9.1 \%(n=3)$ received CHOP+/-R as subsequent therapy after the failure of upfront therapy. During PTLD treatment, overall $45.5 \%(n=15)$ received $\mathrm{CHOP}+/-\mathrm{R}$, which was the most commonly used regimen. This was followed by $\mathrm{R} / \mathrm{C}$ (rituximab, cyclophosphamide) and R-CVP (rituximab, cyclophosphamide, vincristine, prednisone) in 9.1\% (n=3) each.

At the end of the study, $48.5 \%(n=16)$ had a complete response and the overall response rate was $51.5 \%$ $(\mathrm{n}=17)$. Table 4 outlines the details of the response to upfront therapy and at the end of treatment.

\begin{tabular}{|c|c|c|c|}
\hline Upfront Therapy & & $\mathbf{n}$ & $\%$ \\
\hline RIS alone & & 5 & 15.2 \\
\hline \multirow[t]{4}{*}{ Chemotherapy } & & 27 & 81.8 \\
\hline & Rituximab & 6 & 18.2 \\
\hline & R+Chemo & 17 & 51.5 \\
\hline & Chemo & 4 & 12.1 \\
\hline Surgery & & 1 & 3.0 \\
\hline
\end{tabular}

\section{TABLE 4: Treatment details of upfront therapy}

RIS: reduced immunosuppression

At the end of the study, $54.5 \%(\mathrm{n}=18)$ patients were alive and of these, 13 patients were alive with PTLD while $39.4(n=13)$ patients had deceased. After PTLD diagnosis, the allograft survived in $84.8 \%(n=28)$ patients. Six point one percent $(6.1 \%)(n=2)$ patients eventually lost their graft after the diagnosis of PTLD and one of those patients was re-transplanted later, without any issues. One patient experienced allograft rejection during PTLD treatment but was salvaged by the use of pulse steroids and increased immunesuppression. Table 5 gives details of the final outcomes of patients and allografts. 


\section{Cureus}

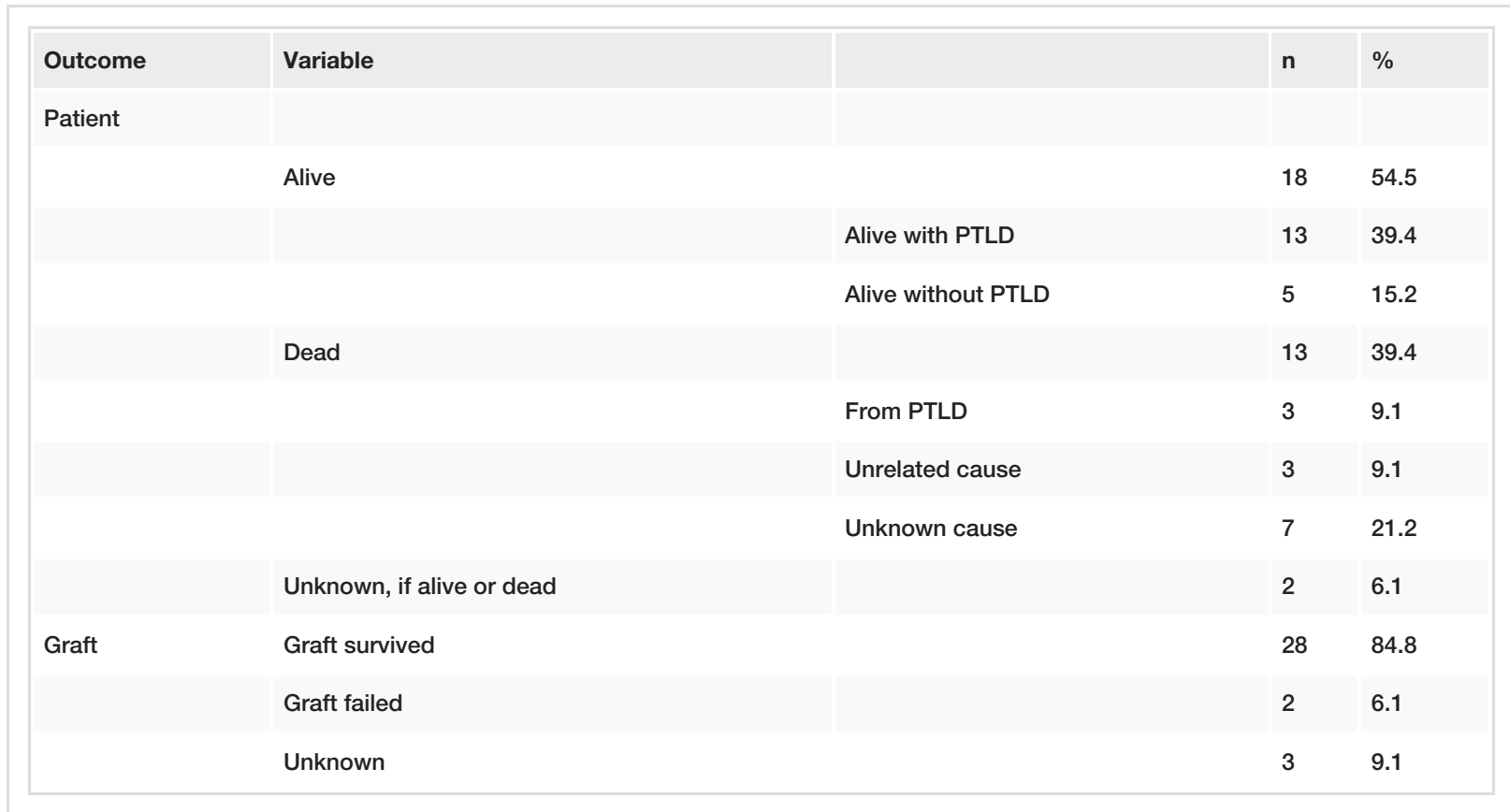

\section{TABLE 5: Final outcomes}

PTLD: post-transplant lymphoproliferative disorder

\section{Statistical analysis}

The Kaplan-Meier (KM) analysis showed a median overall survival time of 5.4 years. Univariate analysis was performed to identify factors associated with survival. The results showed the following patient characteristics to be statistically significant for survival: age at diagnosis of $>65$ years had HR of 3.9 ( $95 \%$ CI: 1.2-13.1, p=0.027), male gender had HR of 6.1 (95\% CI: 1.3-27.6, p=0.019), and PMH of malignancy had HR of 4.8 (95\% CI: 1.0-22.8, p=0.048). Recipient EBV and CMV status were found to be non-significant. The patient's race, ECOG, International Prognostic Index (IPI) score, time from transplant to PTLD diagnosis, type, and previous rejection episodes were non-significant for overall survival. See Figure 1.
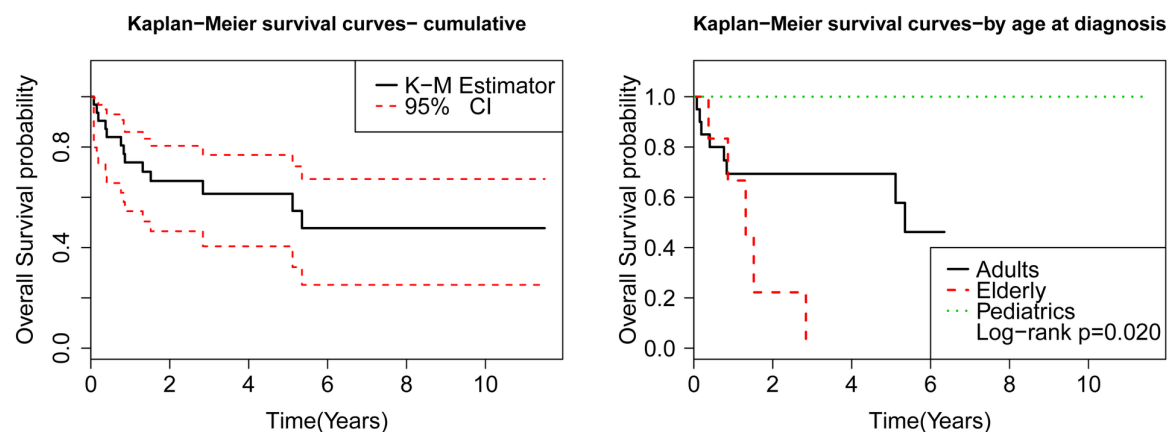

Kaplan-Meier survival curves-by gender

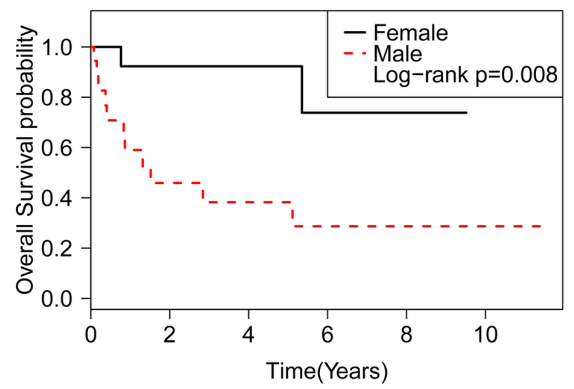

Kaplan-Meier survival curves-by ECOG

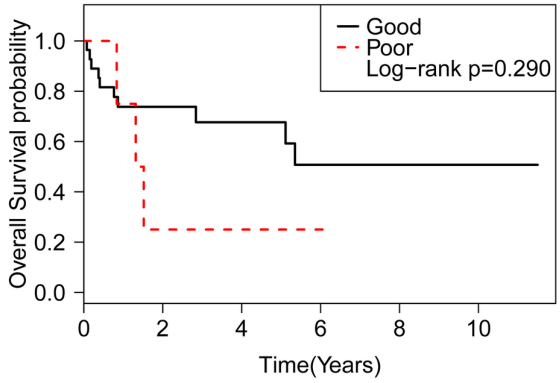

FIGURE 1: Kaplan-Meier survival analysis based on patient 
Analysis of immunosuppression drugs being used at the time of PTLD diagnosis showed that the combination of cyclosporine with azathioprine had HR 5.7 (95\% CI: 1.8-18.4, p= 0.003). If tacrolimus was used in combination or by itself as an immunosuppressant, patients had HR of 0.13 ( $95 \% \mathrm{CI}$ : $0.03-0.57, \mathrm{P}=$ 0.007).

Analysis of the best treatment response showed that patients with an initial best response of PD had an HR of 6.3 (95\%CI: 1.4-28.1, $p=0.01$ ); similarly, patients with the final response as PD had HR: 8.0 (95\% CI: 1.934.1, $\mathrm{p}=0.005$ ). Whereas patients who achieved CR as the final response had an HR of 0.2 (95\% CI: 0.1-0.9, $\mathrm{p}=0.035$ ). The use of rituximab or a different chemotherapeutic regimen was not statistically significant for survival.

Disease characteristics, including Ann Arbor stage, PTLD pathology subtype, CD20 status, EBER status, bulky disease, and central nervous system (CNS) involvement were not significant for survival. Bone marrow (BM) involvement had a statistically significant HR of 12.1 ( $95 \%$ CI $2.2-66.5, p=0.004)$. On a multi-variate analysis, based on the model selection criteria, BM involvement was the only significant factor that remained significant for survival (HR 11.4, p-0.0081). See Figure 2.
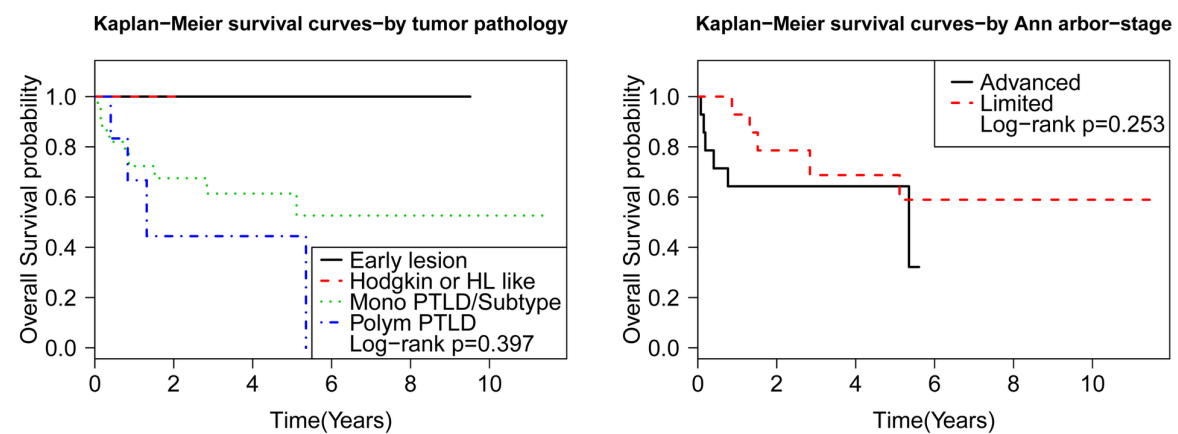

Kaplan-Meier survival curves-by final response

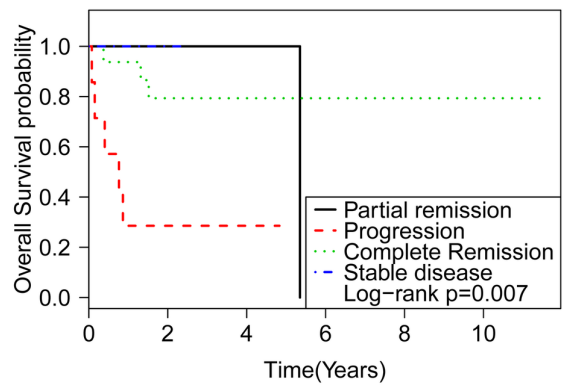

Kaplan-Meier survival curves-by bone marrow

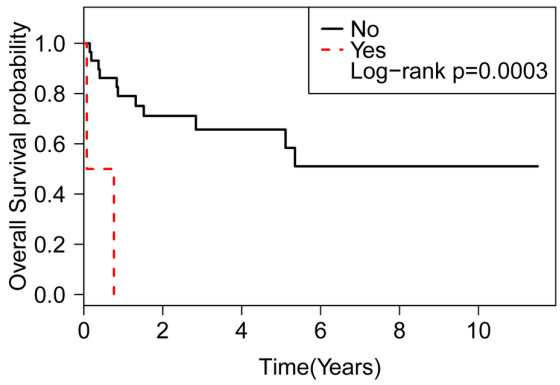

FIGURE 2: Kaplan-Meier (KM) analysis survival based on PTLD characteristics

\section{Discussion}

As the survival of patients after transplant has improved, we have seen PTLD in patients beyond the traditional early-onset and late-onset patient populations [21]. PTLD incidence has a bimodal distribution where there is an increase in incidence within one year of transplant and then another peak, which occurs around five years after transplant. Very-late onset PTLD is defined as PTLD occurring 10 or more years after the transplantation. Over the last two decades, there have been many retrospective studies from individual transplant centers and the factors affecting the survival of early-onset PTLD and late-onset PTLD are wellestablished but there is minimal scientific data for very-late onset PTLD. As prospective studies or clinical trials are difficult to perform in this rare entity, it becomes imperative that we retrospectively explore different subgroups of PTLD to identify different prognostic factors.

In this study, we explored this subgroup of 33 patients with very-late PTLD who were diagnosed between 10 and 18.4 years after their transplantation with a median of 13.3 years, thus indicating that this disease can develop at any point after transplantation, not just the first 10 years. While traditional disease characteristics, such as Ann Arbor stage, number of sites involved, performance status, PTLD pathology 
subtype, CD20 status, EBER status, bulky disease, and CNS involvement, have been found to be statistically significant in prognosticating early and late-onset PTLD, none of these disease characteristics were found to have a statistically significant impact on the prognosis of very-late onset PTLD in our analysis [19,27-28]. Instead, on univariate analysis, advanced age, male sex, type of active immunosuppressant drugs, past history of malignancy, bone marrow involvement, and response to PTLD treatment were significant while on multivariate analysis, only bone marrow involvement at the time of diagnosis was found to be the statistically significant prognostic marker. In fact, patients with advanced Ann Arbor stage had similar survival to those with a limited stage. There is enough scientific data to support that EBV plays a significant role in the pathogenesis of PTLD, but its role as a prognostic factor is questionable [6,24]. That significance appears to decrease with time, as the EBV status of the recipient is non-significant in the cases of very-late onset PTLD. Performance status is a known significant prognostic factor but was not found to have an effect on the survival of patients that presented with very-late onset PTLD.

Multiple previous studies have shown that different immunosuppressive agents also affect survival and, in fact, RIS is usually employed as the first strategy for the treatment of PTLD, either alone or in combination with chemoimmunotherapy $[9,29]$. While the reduction in immunosuppression helps with PTLD treatment by improved host immunity, it also increases the risk of allograft rejection and, sometimes, it is hard to achieve a delicate balance [29]. Our patient population developed PTLD more than 10 years of transplant, at which time, patients have been exposed to prolonged immunosuppression over the years. Various previous studies have explored the risk of PTLD with the use of induction immunotherapy and different immunosuppressive agents as maintenance immunosuppression but there is limited data on the impact of different immunosuppressive agents on the survival of patients with PTLD [5,30]. We found that the use of induction immunotherapy, previous episodes of acute rejections, or chronic rejection did not affect survival. Interestingly, the use of cyclosporine with azathioprine in combination at the time of diagnosis was a statistically significant worse prognostic factor (HR 5.7, 95\% CI: 1.8-18.4, p=0.003) while the use of tacrolimus at the time of PTLD diagnosis, either in combination or by itself, was associated with improved overall survival (HR of $0.13,95 \% \mathrm{CI}: 0.03-0.57, \mathrm{P}=0.007$ ). This finding is interesting, as previous studies have shown that the use of tacrolimus as an immunosuppressive agent is associated with a five-fold increase in the risk of PTLD [30]. This finding suggests the role of immunosuppression over a prolonged time and choice of agents can affect the survival of PTLD significantly. It was interesting to see that after 10 years of transplant, the risk of allograft rejection and failure was so less. Of 33 patients, only one patient experienced acute rejection and, eventually, only two patients lost graft function but one was re-transplanted after PTLD treatment. This finding emphasizes that PTLD treatment likely does not pose a significant risk of graft rejection or failure in a patient who develop PTLD 10 years post-transplant. We also noticed that CD20 positivity or the use of rituximab or choice of different chemotherapeutic agents did not affect survival. However, we did find that the initial best response after the first treatment strategy was associated with survival. Patients who progressed with the first line of treatment had an HR of 6.3 (95\% CI: $1.4-28.1, \mathrm{p}=$ 0.015 ) and tend to do poorly even after other lines of treatment.

In summary, the data from our study shows that the traditional prognostic factors known for early or late PTLD are likely not applicable to this subgroup of very-late PTLD, as these patients are usually older and have been on relatively longer immunosuppression. After evaluating the prognostic factors of very lateonset PTLD, it appears that it is a third distinct subtype of PTLD.

\section{Study limitations}

This study is retrospective in nature and thus carries all the inherent limitations of a retrospective study. Although data collection was robust, there is always clinically relevant information that is not available in medical records. As such, we do note that the evidence from this study is not as rigorous as from a randomized controlled trial (RCT) but given the rarity of very-late PTLD, a retrospective analysis, as conducted by the researchers, is the most practical method of obtaining a clinically meaningful insight into the problem. Another limitation is the small number of patients, however, there is a very small subgroup of patients who have developed very-late PTLD when compared to all patients with PTLD (a very rare group in and of itself). Our literature search did not show any similar studies from the United States.

\section{Conclusions}

As the survival of transplant patients improves, the incidence of PTLD diagnosed after many years of transplant is rising. Very-late onset PTLD is a minimally researched subtype of PTLD. We identified various prognostic factors in this subgroup that are different from the known prognostic factors for PTLD and should be taken into consideration for the clinical course and treatment of very-late onset PTLD.

\section{Additional Information \\ Disclosures}

Human subjects: Consent was obtained by all participants in this study. Institution Review Board (IRB) at the University of Florida, Gainesville, FL issued approval IRB201300065. Ethics approval and consent to participate: This study was approved by the Institution Review Board (IRB) at the University of Florida, Gainesville, FL, and all standard ethical guidelines were followed. A full waiver of informed consent was 
obtained. Animal subjects: All authors have confirmed that this study did not involve animal subjects or tissue. Conflicts of interest: In compliance with the ICMJE uniform disclosure form, all authors declare the following: Payment/services info: All authors have declared that no financial support was received from any organization for the submitted work. Financial relationships: All authors have declared that they have no financial relationships at present or within the previous three years with any organizations that might have an interest in the submitted work. Other relationships: All authors have declared that there are no other relationships or activities that could appear to have influenced the submitted work.

\section{References}

1. Na R, Grulich AE, Meagher NS, McCaughan GW, Keogh AM, Vajdic CM: De novo cancer-related death in Australian liver and cardiothoracic transplant recipients. Am J Transplant. 2013, 13:1296-1304. 10.1111/ajt.12192

2. Cockfield SM: Identifying the patient at risk for post-transplant lymphoproliferative disorder . Transpl Infect Dis. 2001, 3:70-78. 10.1034/j.1399-3062.2001.003002070.x

3. Curtis RE, Travis LB, Rowlings PA, et al.: Risk of lymphoproliferative disorders after bone marrow transplantation: a multi-institutional study. Blood. 1999, 94:2208-2216.

4. Caillard S, Lamy FX, Quelen C, et al.: Epidemiology of posttransplant lymphoproliferative disorders in adult kidney and kidney pancreas recipients: report of the French registry and analysis of subgroups of lymphomas. Am J Transplant. 2012, 12:682-693. 10.1111/j.1600-6143.2011.03896.x

5. McDonald RA, Smith JM, Ho M, et al.: Incidence of PTLD in pediatric renal transplant recipients receiving basiliximab, calcineurin inhibitor, sirolimus and steroids. Am J Transplant. 2008, 8:984-989. 10.1111/j.16006143.2008.02167.x

6. Dierickx D, Tousseyn T, Sagaert X, et al.: Single-center analysis of biopsy-confirmed posttransplant lymphoproliferative disorder: incidence, clinicopathological characteristics and prognostic factors. Leuk Lymphoma. 2013, 54:2433-2440. 10.3109/10428194.2013.780655

7. Knight JS, Tsodikov A, Cibrik DM, Ross CW, Kaminski MS, Blayney DW: Lymphoma after solid organ transplantation: risk, response to therapy, and survival at a transplantation center. J Clin Oncol. 2009, 27:3354-3362. 10.1200/JCO.2008.20.0857

8. Evens AM, David KA, Helenowski I, Nelson B, Kaufman D, Kircher SM: Multicenter analysis of 80 solid organ transplantation recipients with post-transplantation lymphoproliferative disease: outcomes and prognostic factors in the modern era. J Clin Oncol. 2010, 28:1038-1046. 10.1200/JCO.2009.25.4961

9. Jain A, Nalesnik M, Reyes J, et al.: Posttransplant lymphoproliferative disorders in liver transplantation: a 20-year experience. Ann Surg. 2002, 236:429-436. 10.1097/00000658-200210000-00005

10. Franke A, Bishnoi R, Bajwa R, Skelton WB IV, Dang NH, Slayton WB: Outcomes in pediatric patients with post-transplant lymphoproliferative disorder (PTLD): analysis of a 20-year single-institutional experience. Hematol Oncol. 2017, 35:352-352. 10.1002/hon.2439_103

11. Bishnoi R, Bajwa R, Franke AJ, et al.: Post-transplant lymphoproliferative disorder (PTLD): single institutional experience of 141 patients. Exp Hematol Oncol. 2017, 6:1-14. 10.1186/s40164-017-0087-0

12. Bishnoi R, Bajwa R, Franke AJ, et al.: PTLD: survival and analysis of prognostic factors in a cohort of 138 patients from a single institution. J Clin Oncol. 2017, 35:e19048. 10.1200/JCO.2017.35.15_suppl.e19048

13. Faull RJ, Hollett P, McDonald SP: Lymphoproliferative disease after renal transplantation in Australia and New Zealand. Transplantation. 2005, 80:193-197. 10.1097/01.TP.0000165098.49658.F3

14. Morton LM, Landgren O, Chatterjee N, Castenson D, Parsons R, Hoover RN, Engels EA: Hepatitis C virus infection and risk of posttransplantation lymphoproliferative disorder among solid organ transplant recipients. Blood. 2007, 110:4599-4605. 10.1182/blood-2007-07-101956

15. Blaes AH, Morrison VA: Post-transplant lymphoproliferative disorders following solid-organ transplantation. Expert Rev Hematol. 2010, 3:35-44. 10.1586/ehm.09.76

16. Paranjothi S, Yusen RD, Kraus MD, Lynch JP, Patterson GA, Trulock EP: Lymphoproliferative disease after lung transplantation: comparison of presentation and outcome of early and late cases. J Heart Lung Transplant. 2001, 20:1054-1063. 10.1016/S1053-2498(01)00314-X

17. Schober T, Framke T, Kreipe H, et al.: Characteristics of early and late PTLD development in pediatric solid organ transplant recipients. Transplantation. 2013, 95:240-246. 10.1097/TP.0b013e318277e344

18. Quinlan SC, Pfeiffer RM, Morton LM, Engels EA: Risk factors for early-onset and late-onset post-transplant lymphoproliferative disorder in kidney recipients in the United States. Am J Hematol. 2011, 86:206-209. 10.1002/ajh.21911

19. Ghobrial IM, Habermann TM, Macon WR, et al.: Differences between early and late posttransplant lymphoproliferative disorders in solid organ transplant patients: are they two different diseases?. Transplantation. 2005, 79:244-247. 10.1097/01.TP.0000144335.39913.5C

20. Peters AC, Akinwumi MS, Cervera C, et al.: The changing epidemiology of posttransplant lymphoproliferative disorder in adult solid organ transplant recipients over 30 years: a single center experience. Transplantation. 2018, 102:1553-1562. 10.1097/TP.0000000000002146

21. Khedmat H, Taheri S: Very late onset lymphoproliferative disorders occurring over 10 years post-renal transplantation: PTLD.Int Survey. Hematol Oncol Stem Cell Ther. 2011, 4:73-80. 10.5144/16583876.2011 .73

22. Cheung CY, Ma MKM, Chau KF, Chak WL, Wai Tang SC: Posttransplant lymphoproliferative disorders in kidney transplant recipients: a retrospective cohort analysis over two decades in Hong Kong. Oncotarget. 2017, 8:96903-96912. 10.18632\%2Foncotarget.18890

23. Morton M, Coupes B, Roberts SA, et al.: Epidemiology of posttransplantation lymphoproliferative disorder in adult renal transplant recipients. Transplantation. 2013, 95:470-478. 10.1097/TP.0b013e318276a237

24. Leblond V, Dhedin N, Mamzer Bruneel MF, et al.: Identification of prognostic factors in 61 patients with posttransplantation lymphoproliferative disorders. J Clin Oncol. 2001, 19:772-778.

10.1200/JCO.2001.19.3.772 


\section{Cureus}

25. Dotti G, Fiocchi R, Motta T: Lymphomas occurring late after solid-organ transplantation: influence of treatment on the clinical outcome. Transplantation. 2002, 74:1095-1102.

26. Bajwa R, Bishnoi R, Skelton WP, et al.: Retrospective analysis of prognostic factors influencing very late onset PTLD. J Clin Oncol. 2018, 36:e19561. 10.1200/JCO.2018.36.15_suppl.e19561

27. Ghobrial IM, Habermann TM, Ristow KM, Ansell S, Macon W, Geyer S, McGregor C: Prognostic factors in patients with post-transplant lymphoproliferative disorders (PTLD) in the rituximab era. Leuk Lymphoma. 2005, 46:191-196. 10.1080/10428190400012011

28. Choquet S, Mamzer BM, Hermine O, et al.: Identification of prognostic factors in post-transplant lymphoproliferative disorders. Immunosurveillance, Immunodeficiencies and Lymphoproliferations. 2002. 159:67-80. 10.1007/978-3-642-56352-2 9

29. Franke AJ, Bishnoi R, Bajwa R, Skelton WP, Patel N, Slayton WB: Association of allograft rejection with reduction of immunosuppression for post-transplant lymphoproliferative disorder: analysis of a 20-year single-institutional experience. J Clin Oncol. 2017, 35:e19047. DOI: 10.1200/JCO.2017.35.15_suppl.e19047

30. Younes BS, McDiarmid SV, Martin MG, Vargas JH, Goss JA, Busuttil RW, Ament ME: The effect of immunosuppression on posttransplant lymphoproliferative disease in pediatric liver transplant patients. Transplantation. 2000, 70:94-99. 